\title{
A Case Study of ASEAN EFL Learners' Collaborative Writing and Small Group Interaction Patterns in Google Docs
}

\author{
Nakhon Kitjaroonchai ${ }^{1} \&$ Suksan Suppasetseree ${ }^{1}$ \\ ${ }^{1}$ School of Foreign Languages, Suranaree University of Technology, Nakhon Ratchasima 30000, Thailand \\ Correspondence: Nakhon Kitjaroonchai, School of Foreign Languages, Suranaree University of Technology, \\ Nakhon Ratchasima 30000, Thailand.
}

Received: March 30, 2021

Accepted: April 26, 2021

Online Published: April 29, 2021

doi: 10.5539/elt.v14n5p89

URL: https://doi.org/10.5539/elt.v14n5p89

\begin{abstract}
The study investigated the interaction patterns of six ASEAN EFL university students when they worked in small groups on two collaborative writing tasks: a descriptive essay and an argumentative essay. Both groups were homogeneous in terms of gender and heterogeneous in terms of home countries. Data collection included pre- and posttest writing, pre- and post-task questionnaires, participants' work on essays, their reflections, observations, and semi-structured interviews. The students worked on their essays in Google Docs, and the researcher(s) used DocuViz as a tool for visualizations of students' collaborative writing contributions and styles. The findings showed different interaction patterns (a cooperative revision style for Group A vs. a main writer style for Group B) across the two collaborative writing tasks. While revising, both groups added and corrected their essays and employed almost the same writing change functions and language functions, which were suggesting, agreeing, and stating.
\end{abstract}

Keywords: collaborative writing, interaction patterns, ASEAN EFL learners, language functions, writing change functions

\section{Introduction}

In many EFL contexts where English is used infrequently, learners perceive writing as a medium of reinforcement and acquiring language forms and structures (Forbes, 2019). Learners often are taught to write independently due to the preconceived notion that writing is a necessary individual learning activity (Limbu \& Markauskaite, 2015) to express themselves and construct their identity (Li \& Deng, 2019). Writing teachers promote self-directed learning in the classroom to stimulate learners to construct their own knowledge. This autonomous learning process enables learners to acquire knowledge of a foreign language when they are highly motivated (Forbes, 2019; Tseng, Liou, \& Chu, 2020). However, EFL learners display a wide range of learning styles. Those with marginal proficiency need close guidance, scaffolding, and mentoring, particularly with academic writing skills.

Previous studies have shown that collaborative writing (henceforth $\mathrm{CW}$ ) improves the quality of writing involving difficult tasks (Liu, Liu, \& Liu, 2018). It enables a deeper understanding of content and produces better quality of writing (Abe, 2020; Coffin, 2020; Limbu \& Markauskaite, 2015); it increases writing accuracy and vocabulary acquisition (Chen, 2019; Dobao, 2014; Latifi, Norrozi, \& Talaee, 2021; McDonough \& De Vleeschauwer, 2019); and it provides opportunities for learners to brainstorm, give feedback, and create meaning (Alghasab, Hardman, \& Handley, 2019; Bhowmik, Hilman, \& Roy, 2019; Coffin, 2020; Dong, Y., \& Liu, 2020; Storch, 2011). Some researchers have employed web-based collaborative writing (WBCW) tools such as Google Docs (henceforth GD) or Wikis to investigate learners' interaction patterns (Cho, 2017; Li \& Kim, 2016; Li \& Zhu, 2017; Yanguas, 2020) or different styles and characteristics of CW detected through DocuViz, a data visualization tool (Olson, Wang, Olson, \& Zhang, 2017; Warschauer, Yim, Lee, \& Zheng, 2019; Yim, Wang, Olson, $\mathrm{Vu}, \&$ Warschauer, 2017). Although WBCW has gained the interest of researchers due to its writing skill potential (Ansarimoghaddam, Hoon, \& Yong, 2017; McDonough \& De Vleeschauwer, 2019; Yanguas, 2020), scant research has been undertaken on the collaboration and interaction occurring naturally in small groups of tertiary students from linguistically and culturally diverse backgrounds in the Association of Southeast Asian Nations (ASEAN) context. Consequently, the objectives of this study were to explore learners' CW patterns and their use of writing change and language functions throughout the writing process in the EFL classroom context. 


\section{Literature Review}

\subsection{Theoretical Perspective of Collaborative Writing}

Sociocultural theory has been emphasized over the last two decades, in particular CW (Bhowmik et al., 2019; Doboa, 2014; Li, 2014; Li \& Kim, 2016; Lowry, Curtis, \& Lowry, 2004; Storch 2002, 2004, 2011, 2013; Zhang, 2018). Sociocultural theory-based initiatives make learning activity more dynamic and interactive, and learning and development encourages collaboration and interaction among learners (Vygotsky, 1978; Lantolf \& Thorne, 2007). In CW, learners can develop ideas and organize them better and improve linguistic aspects through peer feedback. The quality of the text written is improved in performing difficult tasks (Liu et al., 2018) and more accurate texts are produced (McDonough, De Vleeschauwer, \& Crawford, 2018). CW activities promote social interaction, resource sharing, and knowledge expansion, a phenomenon Vygotsky (1978) called "Zone of Proximal Development" (ZPD).

Vygotsky (1978) claimed that cognitive development is enhanced by ZPD through assistance and scaffolding provided by more capable peers and knowledgeable adults. He believed that individual intellectual development and knowledge discovery are bound to personal experiences and are interceded through social interactions (Chaiklin, 2003; Poehner \& Infante, 2019). Through positive interactions and support, individual learners develop their mental ability at higher levels, such as thinking critically, finding a useful technique to memorize, learning a language in a more productive way, or manipulating the acquired knowledge for future use (Pessoa, Mitchell, \& Miller, 2018). Thus, the concept of ZPD has developed as a driving force to address cognitive development and the process of how humans acquire knowledge.

\subsection{Collaborative Writing in an EFL Context}

In EFL contexts, $\mathrm{CW}$ is considered a crucial writing act and social process that involves a team striving to accomplish a common goal while engaging in negotiation, coordination, and communication during the creation of a shared document (Alhadabi \& Karpinski, 2020; Abrams, 2019; Hsiu-Chen Hsu, 2019; Zhang, 2018). Researchers (e.g., McDonough, De Vleeschauwer, \& Crawford, 2018) revealed that Thai EFL college students produced more accurate texts when they composed paragraphs collaboratively compared to those who worked individually. As advocated by Thongchalerm and Jarunthawatchai (2020), Thai EFL students who were introduced to collaborative and independent construction of texts made a significant improvement in language features and rhetorical organization. The students perceived that $\mathrm{CW}$ during the joint construction could enhance their writing competence and boost their confidence in producing texts in the target language. Likewise, Chen (2019) reported in her study that Chinese EFL university students who were exposed to CW practice outperformed their peers in the control group in terms of language accuracy, fluency, and text quality including organization, vocabulary, and grammar. Furthermore, a meta-analysis of 24 studies investigating the benefits of CW in EFL contexts conducted by Elabdali (2020) revealed that collaboratively written texts were more accurate than individually written texts. More recently, Rahayu (2021) examined the effect of CW embedded with blog online learning on Indonesian EFL students' writing skills. The researcher found that learners who were exposed to the $\mathrm{CW}$ activities combined with blog online outperformed learners in the control group who learned by the conventional method. From these reviewed studies, we may infer that CW has positive effects on EFL learners' writing skills as it improves language accuracy, grammatical units, and overall quality of written texts.

Although a plethora of studies have shown the benefits of CW in EFL classroom contexts, some researchers report its disadvantages. For example, Savasci and Kaygisiz (2019) found that their Turkish EFL learners who were exposed to $\mathrm{CW}$ activities for 14 weeks still preferred individual writing over pair or group writing as they could manage their time more effectively and monitor their self-improvement. The inactive participation of members added workload and more preparation to the team leader (Ghufron \& Ermawati, 2018), the disputed ideas impelled members to discontinue the group work (Wang, Tan, \& Lu, 2017), or low achievers become free-riders (Lewis, 2006). Additionally, Le, Janssens, and Wubbels (2018) found that the Vietnamese university students lacked interpersonal and teamwork skills when engaged in group work in that mostly completed a collaborative task by high-skilled members. From the synthesis reports of both advantages and disadvantages of $\mathrm{CW}$ in EFL classroom contexts, we may infer that $\mathrm{CW}$ imposes challenges whether or not group writing yields benefit to all collaborators. Thus, more CW studies in Asian contexts need further exploration to enrich the knowledge of cross-cultural collaboration.

\subsection{Google Docs}

Google Docs (GD) facilitates CW and foster writing skills and development among L2 writers (Li \& Storch, 2017; Neumann \& Kopcha, 2019; Yanguas, 2020). It is a free web-based word processor that permits users to 
create, edit, and store or retrieve their cloud-based documents conveniently (Suwantarathip \& Wichadee, 2014). The tool motivates learners to negotiate and interact with each other freely outside the classroom settings when they perform a CW task online, that otherwise would be impossible in a traditional writing classroom (Woodrich \& Fan, 2017). Since this cloud-based tool is well-suited for group activities, researchers have shown growing interest in EFL writing classroom contexts (Abrams, 2019; Cho, 2017; Wang, 2019; Yanguas, 2020). GD is perceived to enhance writing skills as well as create a friendly atmosphere in writing and motivating critical thinking (Liu et al., 2018). It allows multiple contributors working on a shared document to edit each other's work in real-time or at their time of convenience. It was found to benefit students who want to build language abilities in a friendly manner within a low-pressure environment or one without constraints often inflicted by a traditional face-to-face classroom (Suwantarathip \& Wichadee, 2014; Woodrich \& Fan, 2017).

\subsection{Collaborative Writing with DocuViz}

DocuViz is a data visualization tool. It can display the entire revision history in GD (Wang et al., 2015; Yim et al., 2017). DocuViz automatically creates a visual history line graph across different timelines, indicating the authors and their contributions in a group project (Olson et al., 2017). The tool detects all data entered and provides usage statistics related to collaborative revision behaviours, such as the amount of peer editing or the contribution of each collaborator (Krishnan, Cusimano, Wang, \& Yim, 2018; Olson et al., 2017; Yim et al., 2017). DocuViz has enabled writing teachers to visualize group interaction, member contributions, and assist in understanding L2 writing behaviour. Therefore, it can be used to help learners improve their writing skills (Olson et al., 2017), as a consequence of the visualization of changes or edits made to the shared document over time (Wang et al., 2015; Warschauer et al., 2019).

\subsection{Language Functions in Peer Interaction}

Learners working in pairs or groups display different patterns of interaction (Storch, 2002, 2004, 2011, 2013). The form depends on the type of task or working modes or competency of the collaborators (Zhang, 2019). Inevitably, CW language functions are widely used across small groups while negotiating their collaborative tasks. Commonly used functions are acknowledging, agreeing, clarifying, confirming, disagreeing, elaborating, eliciting, encouraging, greeting, justifying, questioning, requesting, and suggesting. These language functions in small groups bring about various patterns of interaction, which influence the groups' writing product (Li, 2014; Li \& Kim, 2016; Li \& Zhu, 2017).

Dynamic group interactions via Wiki CW tasks have been studied previously (e.g., Li, 2014; Li \& Kim, 2016; Li \& Zhu, 2017; Wang, 2019). Li's (2014) and Li and Kim's (2016) studies revealed that different interaction patterns emerged from the $\mathrm{CW}$ tasks. The various patterns (e.g., collective-active/withdrawn, dominant/defensive-collaborative, expert/novice, and cooperating in parallel) were allocated language functions. These studies were congruent with Storch's (2002) dyadic interaction model containing five types: 1) collaborative, 2) dominant/dominant, 3) dominant/passive, 4) expert/novice, and 5) cooperative. The patterns of peer interaction are gauged by the equality and mutuality of member engagement. Equality represents the level of contribution and the extent to which the task collaborators strive to control the group task, whereas mutuality refers to the degree of collaborator's involvement with others through comments or text interaction. More recently, Abe (2020) examined interactional practices of Japanese EFL learners participating in online CW tasks. $\mathrm{He}$ discovered that changes in online interactional practices depended on the learners' ability to handle online tasks and their time availability. However, the research exploring small group CW styles and interaction patterns of first year international university students from Asian countries is still in its infancy. To bridge this gap, our study attempted to investigate small group $\mathrm{CW}$ styles and interaction patterns of such students with culturally diversity in an English composition course. The researchers further employed DocuViz to examine the writing style characteristics embedded in GD and contributions of participants. The study was driven by sociocultural theory and was carried out at an international university in Thailand. Two research questions were addressed:

1) What patterns of interaction occur when ASEAN EFL learners engage in CW tasks in Google Docs when their contributed texts are analyzed by DocuViz?

2) What are the writing change and language functions used in $\mathrm{CW}$ when learners are engaged in writing tasks?

\section{Methodology}

The present study drew from the embedded case study approach proposed by Yin (2018) and Neumann and Kopcha (2019). Our study explored ASEAN EFL first-year university students' CW in small groups by 
investigating their interaction patterns and language functions used for constructing group tasks in GD. In this paper an embedded case refers to a study that involves more than one group. Small groups engaging in $\mathrm{CW}$ tasks are considered subcases (Yin, 2018), with each group as a bounded system (Li, 2014; Yin, 2018). The study was bounded by time (12 weeks), and setting (an international university in central Thailand).

\subsection{The Setting and Writing Tasks}

Seventeen first-year undergraduate students in a three-credit English composition course were involved (first semester, 2019-2020). The participants were invited to take a 60-minute pretest writing of 250-300 words in the university computer lab prior to engaging in the $\mathrm{CW}$ tasks. The topic of the pretest writing was "All levels of education, from primary school to university education, should be free of charge". Since the study focused on an embedded case study over an extended engagement period, two CW tasks were required, namely, descriptive and argumentative essays, spanning ten weeks. In the two $\mathrm{CW}$ assignments, the researchers assigned three modified controlled topics for each essay derived from the textbook entitled Great Writing 5: From Great Essay to Research, by Folse and Pugh (2020). The short-listed topics on the descriptive essay were (1) a birthday party, (2) studying for good grades in college, and (3) the freshmen welcome party. Each group could choose one of the topics. Likewise, the three shortlisted topics on the argumentative essay were (1) should the university serve non-vegetarian menu items? (2) should curfews be imposed on campus?, and (3) should English be a medium of instruction in all classes? Three optional essay topics were given to offer learners a choice on familiar topics. The researchers created GD files for each group to complete the work within three weeks for each task. In Week 12 , the participants were asked to write a 60-minute posttest writing of 250-300 words on the same topic. The researchers used Jacob et al.'s (1981) Composition Analytic Scoring Rubric consisting of five components: content $(30 \%)$, organization $(20 \%)$, vocabulary $(20 \%)$, language use $(25 \%)$, and mechanics $(5 \%)$ to assess the participants'pretest and posttest writing performance.

\subsection{Participants and Group Formation}

The participants involved 10 males and seven females. They were from nine Asian countries, namely, Cambodia (1), China (1), Indonesia (1), Laos (3), Malaysia (1), Myanmar (1), Taiwan (1), Thailand (7), and Vietnam (1). The participants' ages ranged from 18 to 21 at the time the study took place. Their English proficiency levels ranged from pre-intermediate to upper intermediate [equivalent to A2-B2 based on the Common European Framework of Reference for Languages (CEFR) scale] as evidenced by their International English Language Testing System (IELTS) band scores adopted by the university where this study took place. Participants were divided into groups of three or four, as recommended by previous researchers (Dobao, 2012, 2014; Li \& Zhu, 2017). Each group formed its own team, but it had to contain at least one member from a different nationality. Gender issues were not controlled. Group members could withdraw their participation during the $\mathrm{CW}$ process if they encountered conflicts.

\subsection{Group Selection for Case Study}

Five groups were formed: three groups (Groups A, B, and D) had three members each and two groups had four members each (Groups $\mathrm{C}$ and $\mathrm{E}$ ). It is worth noting that three learners - one from Group C, one from Group D, and another from Group E - failed to engage in the first task, and later, two of these learners (one each from Groups D and E) deliberately withdrew from their second CW task due to conflicts with teammates. Furthermore, other members from these two teams abstained from employing language functions on task negotiation, but rather divided up the work and compiled them into blocks for both tasks without interaction. The member from Group $\mathrm{C}$ who failed to participate in the first task did not show interaction with his peers in the second task either. Thus, data sources from these three groups were deficient and invalid for investigation since one of the research aims was to investigate language functions used when the team performed a CW task in a natural setting without the instructor-researcher's interventions. This restricted the researchers to examining the two remaining groups consisting of Group A and Group B with in-depth investigations into their interactions across the two CW tasks. Group A consisted of three male students from Indonesia, Laos, and Thailand, whereas Group B consisted of three female students from Laos, Malaysia, and Thailand. Focusing on the two groups would allow the researchers to provide a dense description (Lincoln \& Guba, 1985), which is crucial for a case study (Li \& Zhu, 2017). Of these six participants, only one person (Sak) had used GD for a group reading project prior to joining this study. The profile of the participants from the selected groups engaged in the case study is displayed in Table 1. 
Table 1. Profile of the Participants from Group A and Group B

\begin{tabular}{|c|c|c|c|c|c|c|c|c|c|c|}
\hline Group & Pseudonym & Nationality & Gender & $\begin{array}{l}\text { IELTS } \\
\text { overall } \\
\text { band } \\
\text { score }\end{array}$ & $\begin{array}{l}\text { English Proficiency } \\
\text { (self-evaluation) }\end{array}$ & $\begin{array}{l}\text { No. of } \\
\text { years of } \\
\text { learning } \\
\text { English }\end{array}$ & $\begin{array}{l}\text { Major of } \\
\text { study }\end{array}$ & $\begin{array}{l}\text { Preferred } \\
\text { learning } \\
\text { style }\end{array}$ & $\begin{array}{l}\text { Attitude } \\
\text { towards } \\
\mathrm{CW} \\
\text { (pre-task) }\end{array}$ & $\begin{array}{l}\text { Attitude } \\
\text { towards } \\
\mathrm{CW} \\
\text { (post-task) }\end{array}$ \\
\hline \multirow{3}{*}{ A } & Sak & Lao & $\mathrm{M}$ & 6.0 & Intermediate & 9 & ENT & Mixed & Positive & Positive \\
\hline & Suwit & Thai & M & 4.0 & Pre-intermediate & 12 & ENG & Group & Positive & Positive \\
\hline & Farel & Indonesian & M & 6.5 & Upper-intermediate & 12 & $\mathrm{ACCT}$ & Mixed & Positive & Positive \\
\hline \multirow{3}{*}{ B } & Jannah & Malaysian & $\mathrm{F}$ & 6.5 & Upper-intermediate & 10 & ENG & Self & Positive & Positive \\
\hline & Phannee & Thai & $\mathrm{F}$ & 4.5 & Intermediate & 8 & ENG & Mixed & Neutral & Neutral \\
\hline & Ruethai & Lao & $\mathrm{F}$ & 4.0 & Pre-intermediate & 4 & EDU & Mixed & Positive & Positive \\
\hline
\end{tabular}

* ACCT $=$ Accounting, CIS= Computer Information System, EDU $=$ Education, ENG= English, ENT= Entrepreneurship * Mixed $=$ Prefer both individual and group work

\subsection{Data Collection}

The two CW tasks spanned twelve weeks. In the first week, a-three-hour orientation to group writing in GD was provided to familiarize the participants with online collaborative work. In week two, small groups were established, and participants signed an informed consent form voluntarily. Then they completed a pre-task questionnaire to provide participant background information. In the third week, the students commenced work on a descriptive essay, which was to be completed in three weeks at their convenient time. In week six, they wrote a reflection on their perceptions toward CW Task 1. Engagement with the second task occurred from weeks seven to nine. In week 10, they wrote a reflection addressing similar issues of their perceptions toward the group work and their $\mathrm{CW}$ experiences on the second task and completed the post-task questionnaire. During weeks 11 to 12, semi-structured interviews were completed with the six participants to enhance understanding of their perceptions toward $\mathrm{CW}$ experiences as well as triangulate data sources and validate the research findings.

\subsection{Data Analysis}

To achieve the goals of this study, we employed multiple data sources that included CW in GD revision history, data visualization charts created by DocuViz, pre- and posttest writing, pre- and post-task questionnaires, semi-structured interviews, and student reflections to (1) explore patterns of interaction when ASEAN learners in small groups construct $\mathrm{CW}$ essays via GD, and (2) investigate the writing change functions and language functions used in CW tasks when learners were engaged in group work. The work of Li (2014), Li and Kim (2016), and Storch (2002) was used as a guide to investigate interaction patterns to answer Research Question 1. Patterns of interaction were used that included mutuality and equality. We adapted the analytical approach and interpretations of "mutuality" and "equality" from Li and Kim's (2016) study. In language functions, mutuality was indicated by initiating versus responding actions, and equality was assessed by language functions and frequency counts per person. In writing change functions, mutuality was assessed by analyzing self-versus changes to the writing of others, and equality measures considered change functions, their frequency, and the percentage contribution to the final draft. We used DocuViz visualizations to examine the CW styles. This permitted an understanding to be developed on how these learners co-constructed texts in GD files. Li and Zhu's (2017) taxonomy of writing change and language functions was used to address Question 2 to understand how learners employed writing change acts and language functions to co-construct their essays. To establish inter-rater reliability and inter-rater agreement, both researchers coded $20 \%$ of the data both in writing change functions and language functions employed by the groups. The results of Cohen's Kappa reliability index analysis reached $90 \%$. Any discrepancies were resolved through a consensus discussion. We graded the pre- and posttest writing using Jacob et al.'s (1981) Composition Analytic Scoring Rubric, and the average test scores were used. The taxonomies of writing change functions and language functions are shown in Tables 2 and 3.

Table 2. Taxonomy of Writing Change Functions (adopted from Li \& Zhu, 2017)

\begin{tabular}{ll}
\hline Writing Change Functions & Definitions \\
\hline Adding & Adding or contributing new content or texts initially produced by peers or self \\
Correcting & Correcting grammatical errors or other mistakes on language mechanics \\
Deleting & Eliminating content or texts initially produced by peers or self \\
Rephrasing & Expressing or stating ideas in different words but keeping original meaning \\
Reordering & Restructuring content or reorganizing ideas by moving texts around content \\
\hline
\end{tabular}


Table 3. Taxonomy of Language Functions (adopted from Li \& Zhu, 2017)

\begin{tabular}{|c|c|c|}
\hline \multicolumn{2}{|c|}{ Language Functions } & Definitions \& Examples \\
\hline \multirow{12}{*}{ 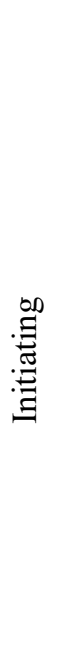 } & Eliciting & Asking or inviting for more comments, thoughts, or ideas from peers \\
\hline & & E.g., How about your opinion? \\
\hline & Greeting & Greeting or saluting peers or team members \\
\hline & & E.g., Hi bro! \\
\hline & Justifying & Verifying or explaining one's viewpoints by giving rationale \\
\hline & & E.g., The point here we need more detail on countries that regulate curfew hours. \\
\hline & Questioning & Making inquiries on statements or texts that are not clear \\
\hline & & E.g., Where is the thesis statement to argue? \\
\hline & Requesting & Making requests or requirements for something related to co-constructed texts \\
\hline & & E.g., Brother, we need more evidence to support the arguments. \\
\hline & Stating & Addressing one's opinions or ideas or information previously discussed \\
\hline & & E.g., Things we need to support such claim are research findings or quotes. \\
\hline \multirow{10}{*}{ 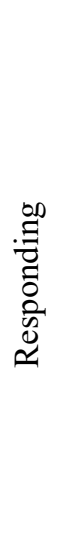 } & Suggesting & Giving suggestions or propositions about content or structure of the essay. \\
\hline & & E.g., We should discuss more to improve this paragraph and make it better. \\
\hline & Acknowledging & Complimenting or phrasing peer's comments, ideas, or supports \\
\hline & & E.g., Great to remind us of this. \\
\hline & Agreeing & Expressing agreement with peer's directions, stance, or viewpoints \\
\hline & & E.g., Yes, you can change it. \\
\hline & Disagreeing & Expressing disagreement with peer's directions, stance, or viewpoints \\
\hline & & E.g., I don't get the meaning you put here. \\
\hline & Elaborating & Giving or adding more information on self or peer's ideas on writing or content \\
\hline & & E.g., There are things we need to discuss more in detail in this paragraph. \\
\hline
\end{tabular}

Note: The examples were directly drawn from the students' $\mathrm{CW}$ tasks without changing any errors.

\section{Results}

Data visualization from GD files was used to interpret the CW styles. This enabled the contribution of each member to be illustrated. Explanations of DocuViz are given in Figure 1. 


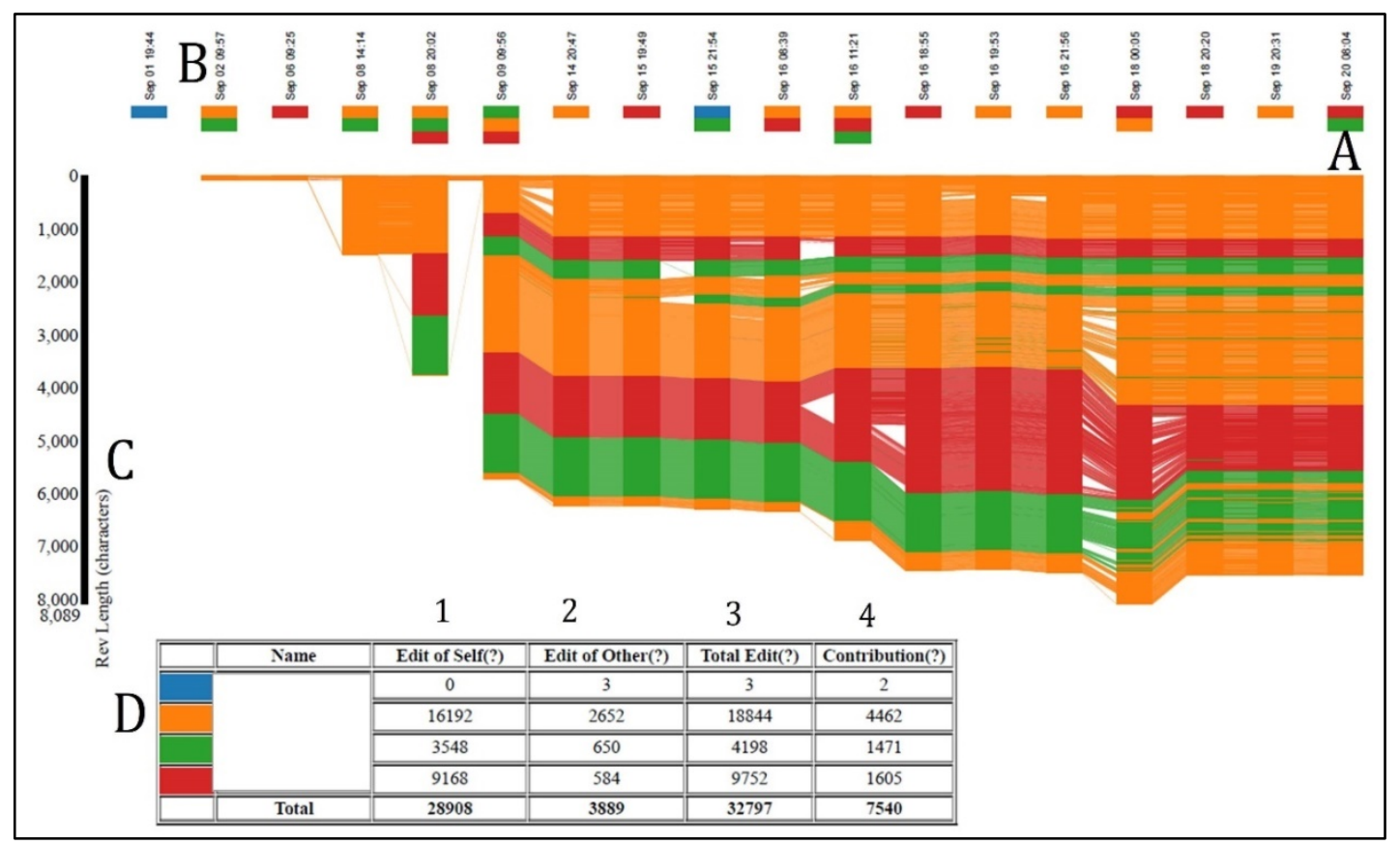

Figure 1. Explanation of DocuViz

The little rectangular bar displayed in different colors at the top of the columns, as shown in letter A, represent a timeline indicating who was in that 'slice' and whether that member contributed then. The colored bars, as shown in letter B, depict the date and time that member logged in and attempted the task. On the far left, character numbers are displayed vertically in descending order from smallest to largest (see letter C). Letter D displays different colors, and each color represents a member participating in the group work. The blue color shown represents the researcher who was an observer. In this chart the number of edits made are shown under various categories (columns 1 to 3 ) and in column 4, each member's contributions to the final version of the task is shown (Krishnan et al., 2018).

\subsection{Analysis of DocuViz and CW Styles}

The CW tasks findings in GD are based on data visualizations revealed by DocuViz. Group A interaction patterns are shown in Figures 2 and 3.

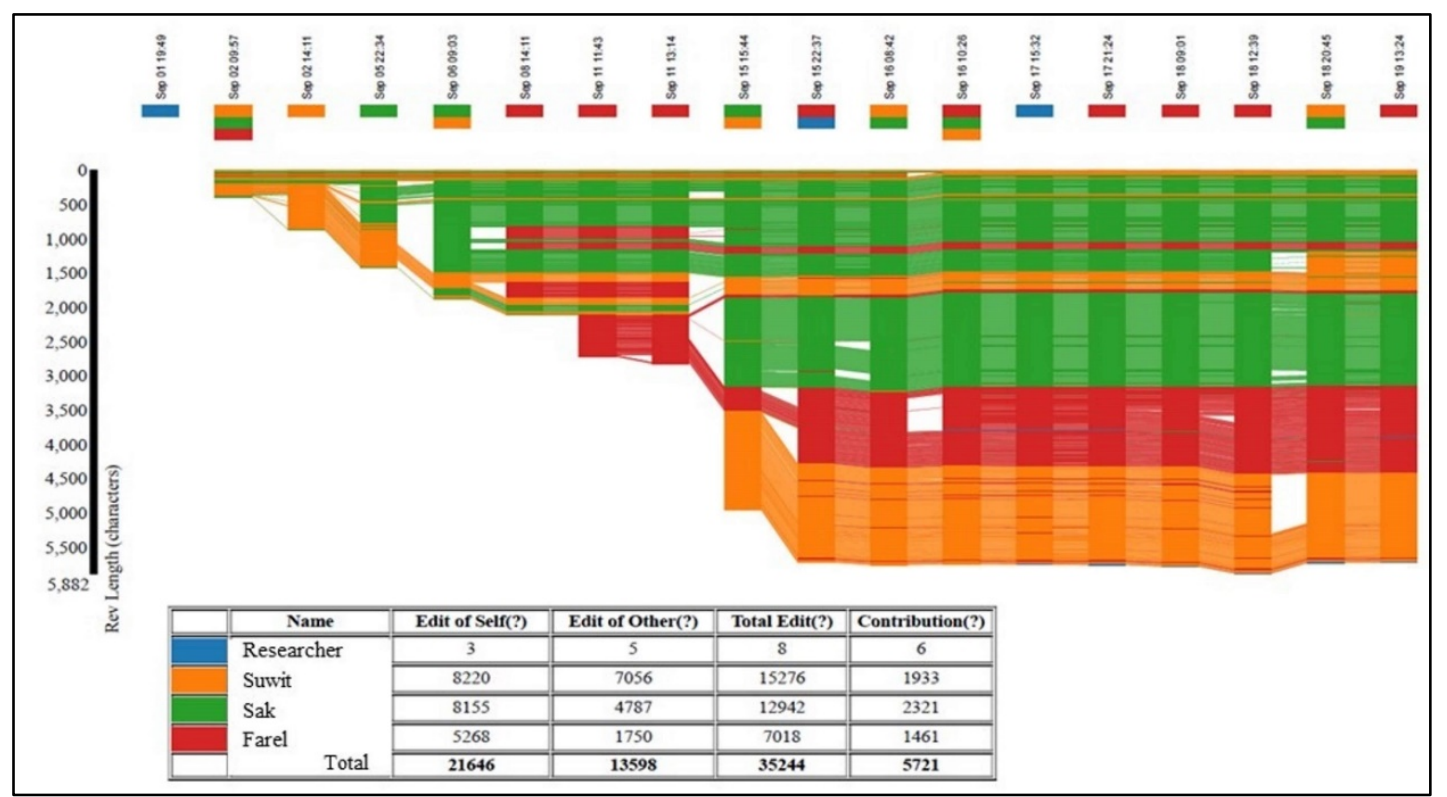

Figure 2. A Line Graph Illustrating Cooperative Revision Style (Group A - CW Task 1) 


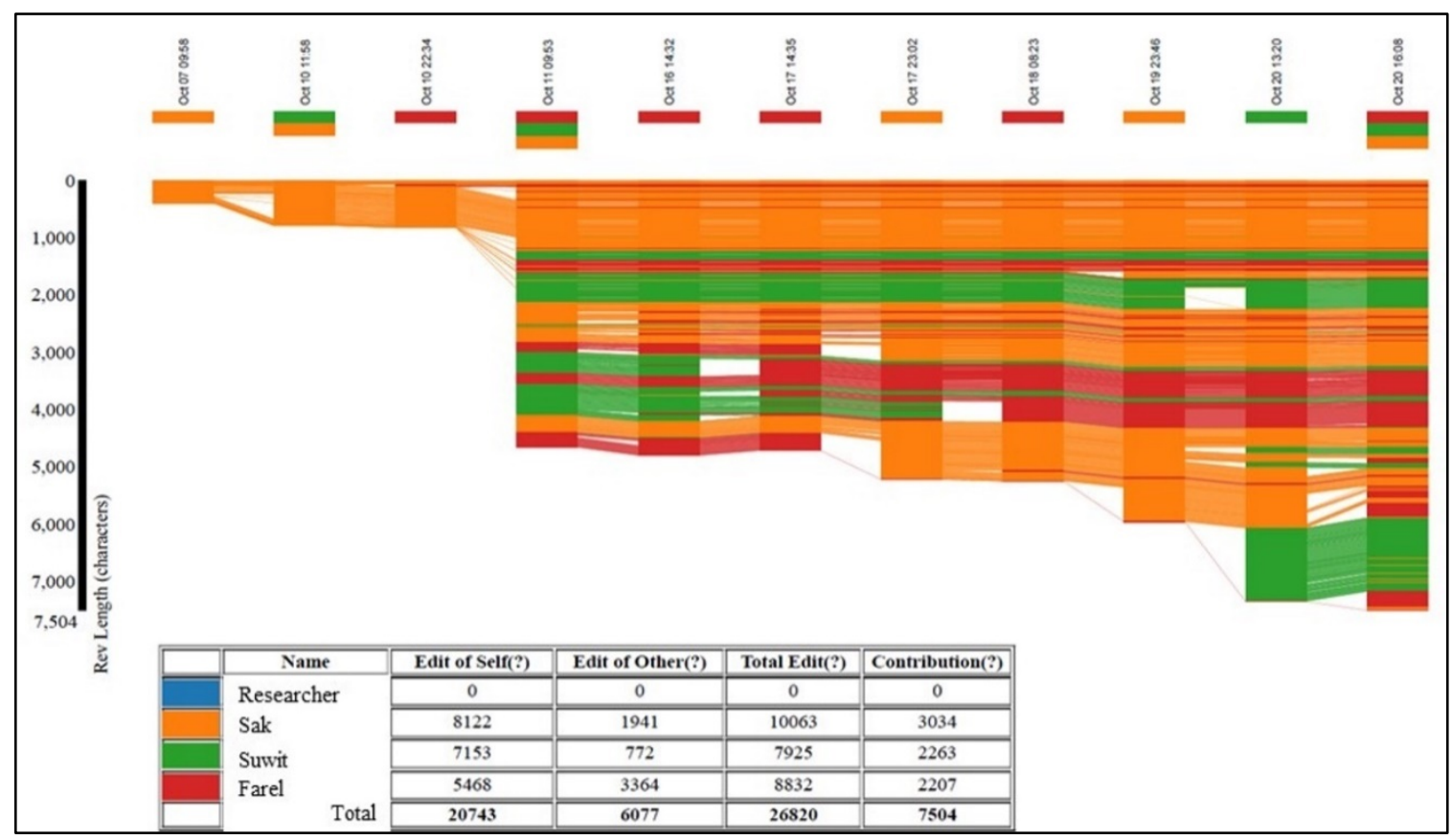

Figure 3. A Line Graph Illustrating Cooperative Revision Style (Group A - CW Task 2)

Group A demonstrated a cooperative revision style in both tasks. They worked on a descriptive essay entitled "studying for good grades in college" taking 17 days (Figure 2). Throughout the writing process, members added text and made changes asynchronously. The group demonstrated active engagement in their group work, but mainly with their own text. In Task 2, Group A used a similar CW style when they composed the argumentative essay, "should the university serve non-vegetarian menu items?" As shown in Figure 3, Task 2 took over 13 days. The proportion of contributions to the CW was similar to that shown for Task 1. Sak contributed the most text. The CW pattern of the second task was again a cooperative revision style.

Unlike Group A, Group B exhibited dissimilar CW styles and interaction patterns. The CW styles and interaction patterns of Group B are illustrated in Figures 4 and 5.

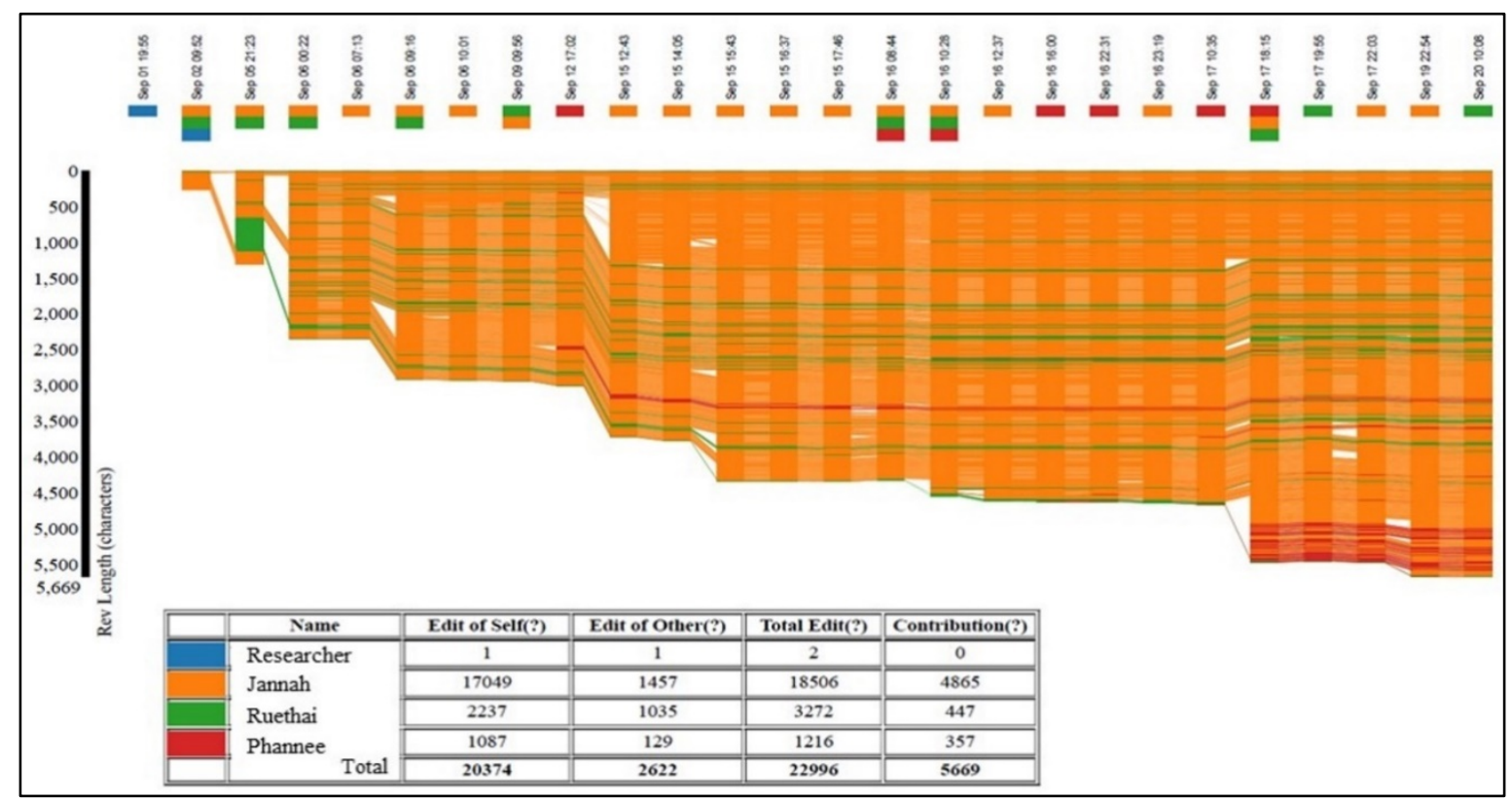

Figure 4. A Line Graph Illustrating Main Writer Style (Group B — CW Task 1) 


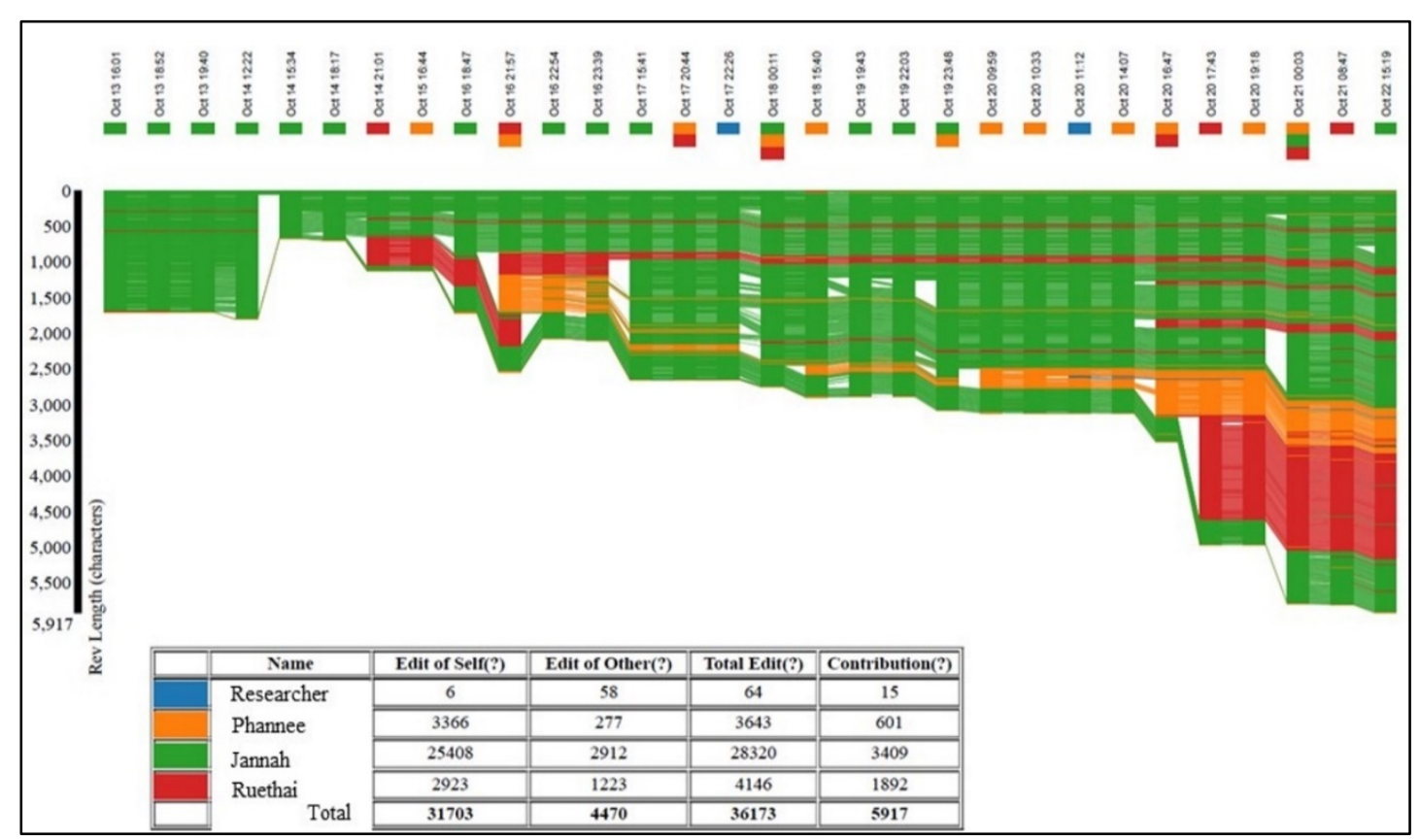

Figure 5. A Line Graph Illustrating Main Writer Style (Group B - CW Task 2)

Group B demonstrated a main writer style in both tasks (see Figures 4 and 5). The group constructed their descriptive essay entitled "a birthday party". The line graph shows that Jannah took control of the work with minimal help from her peers. Figure 4 illustrates that she recorded the highest login attempts (19 times) on the task that spanned over 18 days. On the other hand, Phannee made the least login attempts (seven times) and contributed little. In Task 2, Group B exhibited a similar CW style when they composed an argumentative essay on "should curfews be imposed on campus?" Jannah (green) initiated the topic and the introductory paragraph and a day later Ruethai (red) joined her. Two days after Jannah composed the introduction, Phannee (orange) joined in for the first time, but she made no contribution until three days later. She exhibited her passive role again in Task 2. Table 4 shows members' contributions to the final drafts.

Table 4. An Overview of Group A and Group B Participation and Contributions in CW Tasks

\begin{tabular}{|c|c|c|c|c|c|c|c|c|c|c|c|c|c|}
\hline \multirow[t]{2}{*}{ Group } & \multirow[t]{2}{*}{ Pseudonym } & \multicolumn{2}{|c|}{$\begin{array}{l}\text { Login } \\
\text { attempts }\end{array}$} & \multicolumn{2}{|c|}{$\begin{array}{l}\text { Edit of self (no. } \\
\text { of characters) }\end{array}$} & \multicolumn{2}{|c|}{$\begin{array}{l}\text { Edit of other } \\
\text { (no of } \\
\text { characters) }\end{array}$} & \multicolumn{2}{|c|}{$\begin{array}{l}\text { Total edit (no. } \\
\text { of characters) }\end{array}$} & \multicolumn{2}{|c|}{$\begin{array}{l}\text { Proportion of } \\
\text { contribution } \\
\text { (no. of } \\
\text { character) }\end{array}$} & \multicolumn{2}{|c|}{$\begin{array}{l}\text { Percentage of } \\
\text { contribution } \\
\text { to the final } \\
\text { draft }\end{array}$} \\
\hline & & CW1 & CW2 & CW1 & CW2 & CW1 & CW2 & CW1 & CW2 & CW1 & CW2 & CW1 & CW2 \\
\hline \multirow{4}{*}{ A } & Farel & 10 & 6 & 5,268 & 5,468 & 1,750 & 3,364 & 7,018 & 8,832 & 1,461 & 2,207 & 25.56 & 29.41 \\
\hline & Sak & 7 & 6 & 8,155 & 8,122 & 4,787 & 1,941 & 12,942 & 10,063 & 2,321 & 3,034 & 40.60 & 40.43 \\
\hline & Suwit & 7 & 4 & 8,220 & 7,153 & 7,056 & 772 & 15,276 & 7,925 & 1,934 & 2,263 & 33.84 & 30.16 \\
\hline & Jannah & 15 & 16 & 17,049 & 25,408 & 1,457 & 2,912 & 18,506 & 28,320 & 4,865 & 3,409 & 85.82 & 57.76 \\
\hline \multirow[t]{2}{*}{ B } & Phannee & 7 & 12 & 1,087 & 3,366 & 129 & 277 & 1,216 & 3,643 & 357 & 601 & 6.30 & 10.19 \\
\hline & Ruethai & 6 & 8 & 2,237 & 2,923 & 1,035 & 1,223 & 3,272 & 4,146 & 447 & 1,892 & 7.88 & 32.05 \\
\hline
\end{tabular}

Group A demonstrated a cooperative revision style in both tasks. Contributions did not vary widely among members. Whereas Group B demonstrated a main writer style in both tasks as shown in Table 4, the group's CW tasks were produced predominantly by one member $(85.8 \%$ in Task 1 and $57.7 \%$ in Task 2$)$ with minimal contributions from others. To respond to Research Question 2 on the writing change and language functions employed by the learners, we examined the written texts co-constructed by the teams in GD files and scanned through GD revision history and comments. 


\subsection{Analysis of Writing Change Functions}

The writing change functions produced by Groups A and B in their CW tasks are tabulated and displayed in Table 5.

Table 5. Writing Change Functions Used in CW Tasks Performed by Groups A and B

\begin{tabular}{|c|c|c|c|c|c|c|c|c|c|c|c|c|c|c|c|c|c|}
\hline \multirow{3}{*}{$\begin{array}{l}\text { Writing } \\
\text { Change } \\
\text { Functions }\end{array}$} & & \multicolumn{8}{|c|}{ Group A } & \multicolumn{8}{|c|}{ Group B } \\
\hline & & \multicolumn{2}{|c|}{ Farel } & \multicolumn{2}{|c|}{ Sak } & \multicolumn{2}{|c|}{ Suwit } & \multicolumn{2}{|c|}{ Total } & \multicolumn{2}{|c|}{ Jannah } & \multicolumn{2}{|c|}{ Phannee } & \multicolumn{2}{|c|}{ Ruethai } & \multicolumn{2}{|c|}{ Total } \\
\hline & & $\mathrm{T} 1$ & $\mathrm{~T} 2$ & $\mathrm{~T} 1$ & $\mathrm{~T} 2$ & $\mathrm{~T} 1$ & $\mathrm{~T} 2$ & $\mathrm{~T} 1$ & $\mathrm{~T} 2$ & $\mathrm{~T} 1$ & $\mathrm{~T} 2$ & $\mathrm{~T} 1$ & $\mathrm{~T} 2$ & $\mathrm{~T} 1$ & $\mathrm{~T} 2$ & $\mathrm{~T} 1$ & $\mathrm{~T} 2$ \\
\hline \multirow{2}{*}{ Adding } & Self & 3 & 3 & 2 & 4 & 2 & 2 & 7 & 9 & 8 & 4 & 0 & 3 & 1 & 2 & 9 & 9 \\
\hline & Other & 1 & 3 & 0 & 1 & 0 & 1 & 1 & 5 & 0 & 2 & 2 & 0 & 0 & 3 & 2 & 5 \\
\hline \multirow{2}{*}{ Correcting } & Self & 3 & 0 & 0 & 1 & 0 & 0 & 3 & 1 & 1 & 1 & 0 & 1 & 0 & 1 & 1 & 3 \\
\hline & Other & 2 & 1 & 2 & 2 & 0 & 1 & 4 & 4 & 0 & 1 & 1 & 2 & 3 & 2 & 4 & 5 \\
\hline \multirow{2}{*}{ Deleting } & Self & 1 & 1 & 1 & 1 & 2 & 1 & 4 & 3 & 2 & 1 & 0 & 1 & 0 & 0 & 2 & 2 \\
\hline & Other & 0 & 0 & 0 & 1 & 0 & 0 & 0 & 1 & 1 & 3 & 0 & 0 & 0 & 0 & 1 & 3 \\
\hline \multirow{2}{*}{ Reordering } & Self & 0 & 1 & 0 & 0 & 0 & 0 & 0 & 1 & 0 & 1 & 0 & 0 & 0 & 0 & 0 & 1 \\
\hline & Other & 0 & 0 & 0 & 0 & 0 & 0 & 0 & 0 & 0 & 1 & 0 & 0 & 0 & 0 & 0 & 1 \\
\hline \multirow{2}{*}{ Rephrasing } & Self & 1 & 0 & 3 & 1 & 2 & 0 & 6 & 1 & 7 & 2 & 0 & 0 & 0 & 0 & 7 & 2 \\
\hline & Other & 0 & 2 & 1 & 0 & 0 & 0 & 1 & 2 & 1 & 1 & 1 & 0 & 0 & 0 & 2 & 1 \\
\hline Total & & 11 & 11 & 9 & 11 & 6 & 5 & 26 & 27 & 20 & 17 & 4 & 7 & 4 & 8 & 28 & 32 \\
\hline
\end{tabular}

* T1 = Task 1, T2 = Task

* Group A (20 Self vs 6 Other - Task 1); (15 Self vs 12 Other -Task 2)

* Group B (19 Self vs 9 Other - Task 1): (17 Self vs 15 Other -Task 2)

Group A used identical writing change functions in both tasks (Table 5). The group performed a total of 26 writing change functions ( 20 self vs 6 other) in the first task and 27 in the second task ( 15 self vs 12 other). The most frequently writing change act produced by Group A was adding (41.5\%), whereas the least employed was reordering (1.8\%). Likewise, Group B employed similar writing change functions in both tasks. The team produced a total of 28 writing change acts (19 self vs 9 other) in the first task and 32 acts (17 self vs 15 other). The most frequently writing change acts produced by the group were adding $(41.6 \%)$ followed by correcting (21.6\%) from the two tasks combined. The least used writing change function was reordering (3.3\%).

\subsection{Analysis of Language Functions}

In the following section, the number of language functions employed by Groups A and B are tabulated. Table 6 displays the frequency of language functions employed by Groups A and B over the two CW tasks. The most frequently used language functions produced by Group A were suggesting (28.6\%), followed by agreeing in responding category $(21.4 \%)$. 
Table 6. Frequency of Language Functions Produced by Groups A and B in CW Tasks

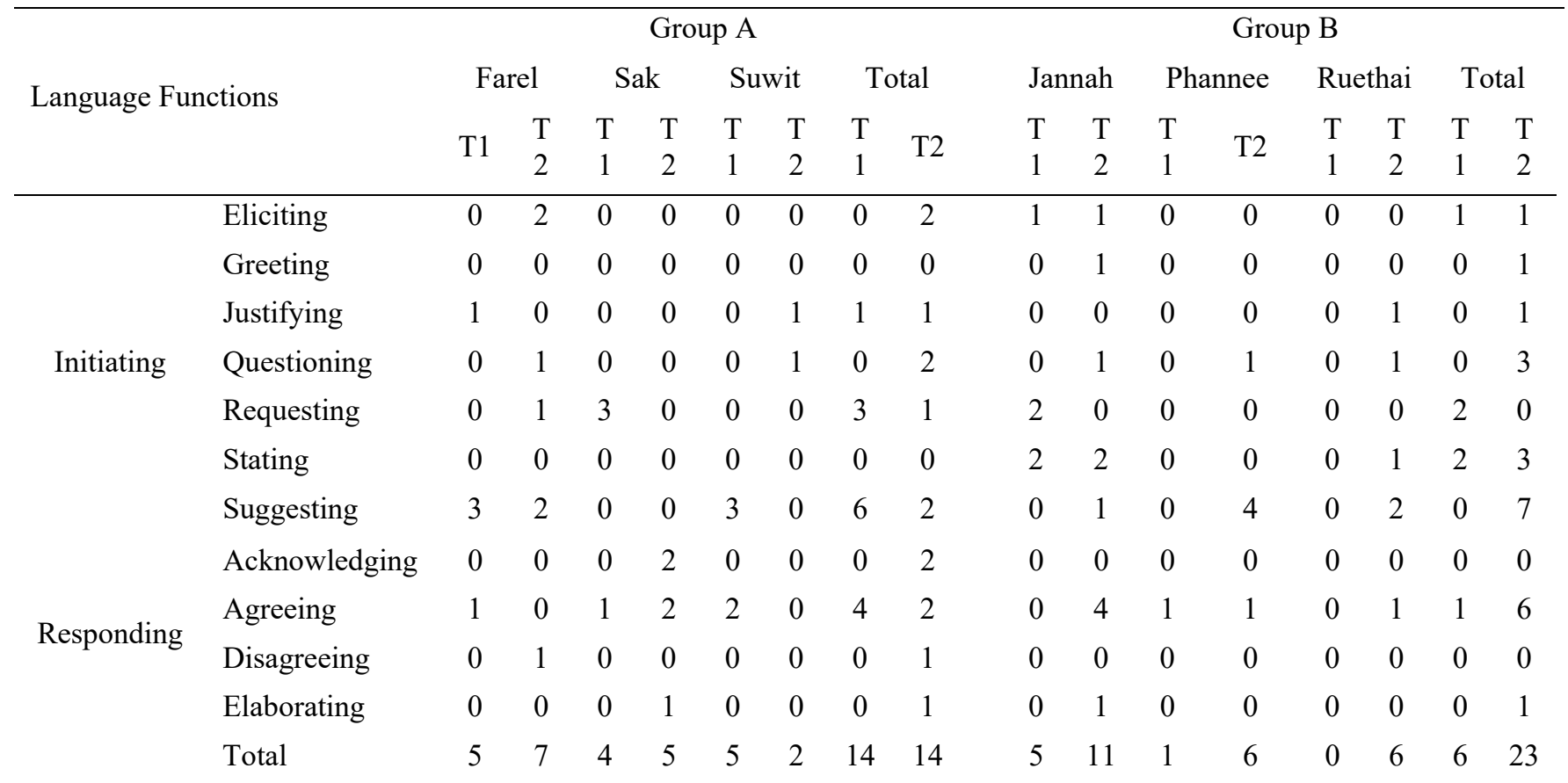

* Group A (10 initiating acts vs 4 responding acts - Task 1); (8 initiating acts vs 6 responding acts - Task 2)

* Group B (5 initiating acts vs 1 responding act - Task 1); (16 initiating acts vs 7 responding acts - Task 2)

Group A demonstrated inactive mutual engagement while attempting to complete Task 1; however, interactions apparently improved in Task 2 as evidenced by their use of writing change and language functions. According to $\mathrm{Li}$ and Kim (2016), mutuality is observed through members' use of initiating versus responding to language functions, and "self versus other writing change functions" (p. 29). From the analysis, Group A produced 26 writing change acts: 20 self vs 6 other (Table 5) and performed 10 initiating language acts and received four responses in Task 1 (Table 6). This implies that the members seldom engaged in their peer's texts. In Task 2, the team employed 27 writing change acts: 15 self vs 12 other (Table 5) and produced six responses to eight initiating acts (Table 6). This shows improvement in group interaction. This may be due to the fact that the members became more familiar with each other after the first task. The nature of argument writing itself impels collaborators to negotiate to reach a consensus when making counterclaims or rebuttals. The members' involvement in text composed by teammates in an interaction is known as "intersubjectivity" (Rommetveit, cited in Li \& Zhu, 2017), which commonly is taken to mean that the members supported each other in text construction.

Group B, on the other hand, employed a total of 29 acts of language functions from both tasks combined (Table 6). In both tasks, the members showed unequal contributions as evidenced by DocuViz (Figures 4 and 5). In Task 1, one member produced five initiating language functions but received only one response from her teammates. Further evidence is noticed in Table 4 that the members' proportion of text contribution was noticeably unbalanced when one member dominated most of the work. In Task 2, the team showed a slight improvement in their interactions when the group employed 16 initiating language functions and received seven responding acts. The members appeared to be more engaged in their peers' contributed texts, as noticed by their use of writing change acts (17 self vs 15 other);

however, texts were mainly contributed by the same member as in Task 1. Thus, the CW style remained unchanged as the main writer style.

\subsection{Analysis of Writing Performance}

Since the study employed an embedded case of two groups with an in-depth analysis, the researchers excluded data from other participants who failed to interact. The researchers reported only the writing performance of members in Groups A and B. The findings of the pretest and posttest writing performances exhibited by the six participants are demonstrated in Table 7. 
Table 7. Results of Learners' Writing Performances by Domain

\begin{tabular}{lllllllll}
\hline Domain & Writing Test & $\mathbf{n}$ & Mean & SD & MD & $\boldsymbol{t}$ & df & $\boldsymbol{p}$ \\
\hline \multirow{2}{*}{ Content } & Pretest & 6 & 17.16 & 2.92 & 5.16 & -16.81 & 5 & .000 \\
& Posttest & 6 & 22.33 & 3.01 & & & & \\
\multirow{2}{*}{ Organization } & Pretest & 6 & 13.83 & 2.13 & & & & \\
& Posttest & 6 & 16.67 & 1.63 & 2.83 & -9.22 & 5 & .000 \\
Vocabulary & Pretest & 6 & 14.00 & 2.00 & & & & \\
\multirow{2}{*}{ Language } & Posttest & 6 & 16.16 & 1.72 & 2.16 & -7.05 & 5 & .001 \\
& Pretest & 6 & 15.16 & 2.48 & & & & \\
Mechanics & Posttest & 6 & 17.83 & 2.56 & -2.67 & -5.39 & 5 & .003 \\
& Pretest & 6 & 3.16 & 0.75 & & & & \\
\hline
\end{tabular}

$* * \mathrm{p}<.001$ (2-tailed) $\quad * \mathrm{p}<.005$ (2-tailed)

As seen in Table 7, the participants' writing performance showed some improvement of the posttest scores for all language domains after engaging in the CW tasks. The average score of the posttest for "content" increased by 5.16 points, whereas the score for "organization" increased by 2.83 points and 2.16 points for "vocabulary". The domain on "language use" improved by 2.67 points in the posttest mean score, and "mechanics" 0.50 score on a five-point scale. The findings were in line with Chen's (2019) and Latifi et al.'s (2021) studies which found that EFL learners who were exposed to CW practice and received peer feedback outperformed their peers who were not, in terms of accuracy and text quality, which includes organization, vocabulary, and grammar when they subsequently produced texts on an individual basis in a delayed post-test writing. In other words, the benefits of $\mathrm{CW}$ tasks can be translated into higher scores on subsequent individual writing. However, the findings of this study cannot be generalizable as it was only a case study involving six ASEAN EFL learners. The summary of the descriptive data of learners' written texts that includes the total of word counts, number of paragraphs, average word counts and paragraphs per student, and mean length of sentence in their pretest and posttest writings is demonstrated in Table 8.

Table 8. Descriptive Data of Learners' Writings $(n=6)$

\begin{tabular}{lllllll}
\hline \multirow{2}{*}{$\begin{array}{l}\text { Students' Writing } \\
\text { Performance }\end{array}$} & \multirow{n}{*}{} & \multicolumn{3}{c}{ Total } & \multicolumn{3}{c}{ Average } \\
\cline { 3 - 7 } & & Word Counts & Paragraphs & Word Counts & Paragraphs & MLS \\
\hline Pretest Writing & 6 & 1,739 & 24 & 289.83 & 4.00 & 24.84 \\
Posttest Writing & 6 & 2,623 & 29 & 437.16 & 4.83 & 18.27 \\
\hline
\end{tabular}

Note: MLS = mean length of sentence (number of words per sentence)

The analysis showed that the participants in this case study developed more extended texts accounted for a total of 2,623 words and 29 paragraphs in the posttest, compared to 1,739 words and 24 paragraphs in the pretest. The increase in texts could provide extended information with supporting details, which can improve the content in their posttest writing. Interestingly, the mean length of sentence was shorter in the posttest writing (18.27 words per sentence). The analysis revealed that the pretest writing contained more run-ons and dependent clauses. However, learners improved their sentence structure although the sentences were shorter but more completed.

\subsection{Explaining Dynamic Goals of Individual Members}

The triangulated data sources from the pre-task and post-task questionnaires, student reflections, observations, and interviews helped explain how individual members in a small group were conceptualized to exhibit such interactions while engaging in CW tasks. Four major themes emerged from our qualitative data analysis of individual student goals regarding fluidity of interaction patterns: getting a good grade for the course, developing writing skills, enhancing learning experience, and completing tasks. Figure 6 exemplifies the goals of individual members' relating to $\mathrm{CW}$ tasks in GD. 


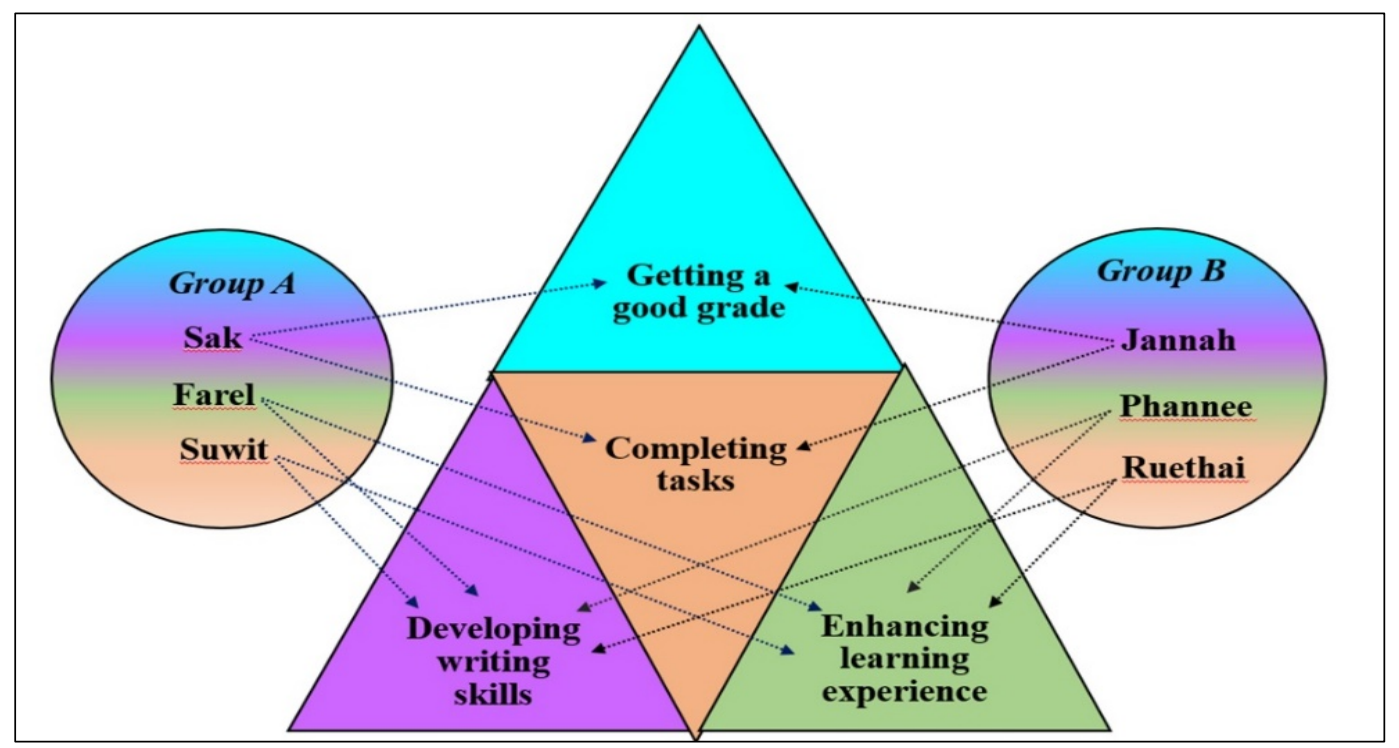

Figure 6. Goals of Individual Members towards CW Tasks

Group A showed positive attitudes towards CW tasks as indicated in the pre-task and post-task questionnaires. The team did not actively engage with members' contributed texts while constructing the first task. However, the group demonstrated improved interaction while performing the second task, as evidenced by their involvement in their group's texts and the increased responses to initiating acts. The analysis of qualitative data on individual learner goals and member's roles enabled us to explain the group's CW style and interaction patterns. Farel and Suwit held similar goals while engaging in CW tasks. Both members perceived that $\mathrm{CW}$ tasks could develop writing skills. Farel indicated, "I can improve my writing when I work with group" (Interview with Farel, November 5, 2019). A similar goal was echoed by Suwit who also claimed that "collaborative work can help me to write better" (Interview with Suwit, November 6, 2019). Farel stated "When I work with friends from different cultures, I can learn from them too". Likewise, Suwit perceived CW tasks helped him to "enhance writing skills and social interaction". This resonates with Zhao (2018) who claimed that social interactions in peer review processes contributed to language enhancement. Farel perceived himself as an active contributor in both tasks. He shared in the interview: "I did my part and gave comments on writing mistakes if I find them." This was evidenced by the employment of language functions and number of login attempts. Likewise, Suwit positioned himself as an amateur writer who was willing to learn from his peers. Sak, on the other hand, possessed divergent goals from his peers. He was cautious and held that gaining a good grade demanded a timely completion of tasks. The triangulated data sources from the interviews and students' reflections indicated that Sak's greater contributions to text and proofreading was positioning himself as an editor and leader to direct others to complete the tasks on time. This finding has been echoed in previous studies (e.g., Alhadabi \& Karpinski, 2020; Dong \& Liu, 2020), which posited that learners with a determined goal paid more attention to academic performance. The triad agreed that $\mathrm{CW}$ tasks generate more ideas and resources. This was evidenced by their increased scores in the posttest writing. The finding is congruent with previous studies (e.g., Bhowmik et al., 2019; Coffin, 2020; Storch, 2011; Wang, 2019), which claimed that CW can provide opportunities for learners to brainstorm for ideas and give feedback that can improve the quality of writing.

Group B members rarely interacted with each other in Task 1, as evidenced by their use of language functions. Furthermore, the team showed inequality in Task 1, as one member controlled the task. In Task 2, the members showed a slight improvement by engaging in the contribution of others as evidenced by their use of writing change functions; however, the group CW style did not shift. Their reflection papers and interviews helped explain the interaction patterns. Jannah positioned herself transparently as a proofreader and editor. Her main goal was to complete the tasks and earn a good grade, which was like Sak's in Group A. In the interview, she stated, "I need to ensure we complete the writing on time and earn a good point even not perfect" (Interview with Jannah, November 6, 2019). Her determined goal propelled her to take control on both tasks. In a different manner, Phannee and Ruethai shared convergent goals. Their goals included developing writing skills and enhancing learning experience. Both positioned themselves as novice contributors and followers who would rather take instructions from their leader. From the interviews and reflection papers, both Phannee and Ruethai acknowledged that Jannah had a better command of English than they. Ruethai shared in the interview that 
"Jannah is much better in English than me, so she can work more...". Her claim was supported by Phannee who stated, "...when I work with someone who has better English, I feel worried". This claim was a primary reason why Phannee and Ruethai were reluctant to contribute. The occurrence impelled Jannah to control the tasks, so the group demonstrated a less collaborative effort compared to Group A.

\section{Discussion}

The aims of this study were to explore the patterns of interaction of ASEAN EFL learners in small groups engaging in $\mathrm{CW}$ tasks in GD and their use of writing change and language functions while performing group tasks. Group A demonstrated a cooperative revision style in both tasks, whereas Group B exhibited a main writer style across the two tasks. These findings are consistent with the results obtained by Li and Zhu (2013) who found stable patterns of interaction in the three small groups they studied with Chinese EFL university students, and Hsiu-Chen (2019) who reported that different types of CW task did not lead to changes in peer interaction patterns. In contrast to Li and Kim (2016) which found the patterns of interaction shifted when a writing task changed. One possible reason was the participants in their study were in similar language proficiency level. Fluidity of $\mathrm{CW}$ occurs on account of the emergence of collaboration, particularly when members collectively search for further information (Li, 2014; Li \& Kim, 2016; Li \& Zhu, 2017). In our study, members with a determined goal of getting a good grade and producing a good quality essay seemed to establish their fixed position and contribute more texts. The findings are in line with previous studies (e.g., Alhadabi \& Karpinski, 2020; Wang, 2019), in which the researchers found that learners with a determined goal of earning good grades would pay more attention to academic performance and actively get engaged in the group work resulting in unaltered collaborative behaviour. Both groups employed similar writing change functions while engaging in two CW tasks. The most writing change acts employed by the groups were adding to self-constructed texts followed by correcting themselves and others. This phenomenon was reported in previous studies (Dobao, 2014; Li \& Kim, 2016; Li \& Zhu, 2017). When learners in small groups were engaged in a CW task, particularly members who were unacquainted with each other, they corrected their own errors and left comments for improvement rather than corrected the mistakes of others. Team collaboration resulted in a more accurate use of language structures (Dobao, 2014; McDonough \& De Vleeschauwer, 2019). Another significant reason why the two groups employed relatively identical writing change functions was due to the lack of academic writing experience. From the observations and the interviews, these six ASEAN EFL learners indicated that they were not properly trained to compose academic essays when they were in high school. Hence, they tended to revise texts mainly at a surface level, such as grammar, spelling, punctuation, and other language mechanics.

\subsection{Learners English Proficiency Shapes Interaction Patterns}

EFL learners with higher English proficiency level were found to take an active role in CW since they had a distinct advantage over their less capable peers in matters concerning linguistic resources. On the contrary, learners perceived to have lower language proficiency were reluctant to contribute for fear of making errors. This was reflected by Group B collaborative behaviour. These findings are congruent with those of previous studies (e.g., Dong \& Liu, 2020; Hsiu-Chen, 2019), in which the researchers found that EFL learners with higher language proficiency level would produce more language-related episodes, put more effort into the work, and resolve language-related issues more successfully. On the contrary, learners with limited linguistic resources passively contributed to the group task (Zhang, 2019). As claimed by Lewis (2006), Asian learners include Indonesian, Lao, Malaysian, and Thai are docile and obedient and they tend to avoid confrontation, save face by speaking less, and show respect to their more knowledgeable peers while engaging in group projects. This phenomenon gives way for high-skilled learners to have more room to contribute and occasionally ignore the efforts of their less capable peers (Ghufron \& Ermawati, 2018; Le et al., 2018). This implies that learners' language proficiency and leadership role exhibited by a more capable writer in the team help shape interaction patterns and influence members' contributions.

\subsection{CW Improves Learners' Writing Performance}

$\mathrm{CW}$ tasks have proven to enhance EFL learners' writing skills on an individual level. The findings are congruent with previous studies (e.g., Alghasab et al., 2019, Chen, 2019; Dobao, 2014; Latifi et al., 2021) which reported that EFL learners who were exposed to CW practice could improve text quality including essay organization and grammar when they subsequently produced texts on an individual basis. We found that learners produced shorter but more accurate and complete sentences. In other words, the benefits of $\mathrm{CW}$ tasks could be translated into higher scores on subsequent individual writing. This might be because the accumulated experiences from co-constructing essays propelled them to internalize knowledge gained into their subsequent writing performance. As advocated by Lantolf and Thorne (2007), learners' cognitive function would process what 
being procured for future performance when the mental process is stimulated which led to increased individual writing. Collaboration allows development to occur first between members at an interpsychological level and then led to development at an intrapsychological level (Vygotsky, 1978; Bikowski \& Vithanage, 2016).

\subsection{The Aspect of Cross-Cultural Collaboration}

Implementing CW activities in a cross-cultural ASEAN EFL classroom where learners are unacquainted with each other due to their cultural differences need the course instructor's close attention (Le et al., 2018; Lewis, 2006). This present study made us aware that exchanging ideas with someone from a different cultural background requires trust and openness. Only two groups out of five produced valid and complete data that met our research objectives, and they were used for our case study. This occurrence signaled that to entrench a successful CW task in a first-year ASEAN EFL university classroom context, teacher intervention is needed. The role of teachers in EFL group writing is crucial for teachers can secure the improvement of member engagement and guide in dialogic interactions (Alghasab et al., 2019; Zhao, 2018) when learners are unfamiliar with cross-cultural collaboration. Without teacher intervention, collaborative efforts in a natural setting would be unlikely to occur. Thus, teachers of a $\mathrm{CW}$ classroom ought to emphasize cross-cultural differences and communication strategies (Lewis, 2006) that could influence group interaction, including the practice of language functions on peer writing that may inculcate learners to become more captivating writers as they learn to comment and respond to suggestions. Furthermore, learners' divergent cultural orientation must be embraced and regarded as assets not as hindrances (Chen \& Sujarittanonta, 2014) to eliminate negative stereotypes; rather, they must show mutual respect and in that they can work in harmony while joining in knowledge creation. In the interviews, these six learners noted that $\mathrm{CW}$ with members from different cultures could enhance their cultural awareness. They considered CW activities across cultural differences are considered new. Farel expressed, "Writing with peers who are different from you is completely new ...there are times we disagree, but we don't want to speak frankly or say no" This indicates that the learner felt uncomfortable to refuse or make negative statements on a person's text. Phannee, who was subservient in both tasks, indicated, "My English is not good, so I just learn and observe from Jannah who has better English." This implies that language proficiency can hamper peer responses and contribution when learners lack confidence or have limited linguistic resources. Therefore, effective peer feedback trainings and using of language functions to improve language features, essay structure, and organization of ideas should be emphasized in an EFL learners' CW classroom to expand learners' knowledge about constructive feedback and hone their writing skills.

\section{Conclusions}

In the research reported, the interaction patterns of ASEAN EFL university students in an English composition class were explored in terms of the performance of CW tasks in small groups using GD. The study was driven by the sociocultural theory that indicated the value of viewing learners' collaboration and interactions and their use of writing change functions and language functions while constructing two academic essays. Through the support of DocuViz and GD revision history, we found that both teams showed dynamic interactions. Qualitative data from the interviews and student reflections indicated that learners' contributions and interaction patterns were influenced vitally by personal goals and their team roles. The cooperative revision style used indicated equality of members' participation in text contributions but unnecessarily high mutuality. By contrast, the main author writing style indicated inequality and non-mutuality. These findings echoed Storch's model of dyadic interaction (Storch, 2011). Usually when a cooperative pattern is utilized, collaborators divide up work and occasionally engage with other's texts. The lack of mutual engagement during task negotiation found in the main writer style is caused by learners' limited language proficiency (Hsiu-Chen, 2019; Zhang, 2019) and on account of their attitudes towards group work.

This study yielded some pedagogical implications. First, the integration of web-based CW tools, such as GD and DocuViz, can monitor members' contributions and raise awareness of their participation. When these tools are implemented effectively in the writing class, they can help eradicate the free-rider problem that is invisible in a traditional writing classroom. GD enables collaboration either in synchronous or asynchronous writing mode beyond classroom boundaries, whereas DocuViz can inform writing teachers how team members revise group work and potentially reveal whether a particular revision pattern or group writing style yields a higher quality of writing. This calls for future research. Secondly, in the present study, we observed small group interactions as an outsider to keeping data from emerging in a natural setting. In other words, there were no comments or feedback provided by the course instructor during the $\mathrm{CW}$ process. This drew an attention to failure stories of cross-cultural collaboration in a natural setting when instructor intervention was absent. The study informed us that when ASEAN EFL learners performed cross-cultural group writing, collaborative efforts would unlikely 
happen unless a team had a supportive leader who took the initiative and stimulated the members in collaborative scaffolding. Therefore, instructor interaction and dialogic feedback must be integrated in ASEAN EFL learners in small group writing when members are unacquainted with each other. Albeit imperfect, this study shed some light on how cross-cultural collaboration in GD can be used to enhance writing performance in L2 writing classroom where learners are culturally and linguistically diverse. Lastly, due to the growing number of international schools, multilingual learners are becoming more common in an EFL classroom today (Conteh, 2019; Sun \& Zhang, 2020). Forming small groups of learners from linguistically diverse backgrounds in a language classroom setting will provide opportunities for L2 learners to exchange cultural values, differences, and develop inter-cultural communication skills as they interact with each other in a target language. Training EFL learners to work collaboratively using online collaborative tools in a multilingual classroom context will prepare them for digital literacy skills, which are essential for future careers in a multicultural world that uses English as its lingua franca.

\section{Limitations}

This study had limitations. First, our case study involved only six ASEAN EFL learners making two small groups. Therefore, the findings cannot be generalizable to other settings with similar contexts. Future researchers should include more participants from different international institutions and extended to ESL/EFL learners outside the Asian continent. Second, only two CW tasks were implemented in the study within a span of twelve weeks. In future studies, a greater variety of academic essay types or other writing genres with a controlled topic could be considered. Task types, mixed-gender groups, and learners' language proficiency should be cautiously manipulated by researchers whose interest dwells on cross-cultural collaboration. More groups might be involved coming from different L1 backgrounds to gather a richer data set and observe the long-terms impact of $\mathrm{CW}$ activities on individual writing performance. Lastly, we used DocuViz to observe the participants' CW styles through color codes. The system is flawed in that DocuViz generates different color codes for the same authors when tasks are shifted. The existing system does not detect comments or chats in the GD revision history due to ethical concerns. Chats or comments entered in the cloud-drive must be analyzed through comment history in GD since DocuViz displays only fundamental information at the surface level. Thus, deeper understanding of group interactions must be analyzed via GD revision history.

\section{Acknowledgements}

We would like to express our sincere gratitude to the editors, the anonymous reviewers, for their insightful and valuable comments on earlier versions of this manuscript. Any remaining errors are our own.

\section{References}

Abe, M. (2020). Interactional practices for online collaborative writing. Journal of Second Language Writing, 49,100752. https://doi.org/10.1016/j.jslw.2020.100752

Abrams, Zs. I. (2019). Collaborative writing and text quality in Google Docs. Language Learning \& Technology, 23(2), 22-42. https://doi.org/10125/44681

Alghasab, M., Hardman, J., \& Handley, Z. (2019). Teacher-student interaction on wikis: Fostering collaborative learning and writing. Learning, Culture and Social Interaction, 21, 10-20. https://doi.org/10.1016/j.lcsi.2018.12.002

Alhadabi, A., \& Karpinski, A. C. (2020). Grit, self-efficacy, achievement orientation goals, and academic performance in University students. International Journal of Adolescence and Youth, 25(1), 519-535. https://doi.org/10.1080/02673843.2019.1679202

Ansarimoghaddam, S., Hoon, T. B., \& Yong, M. F. (2017). Collaboratively composing an argumentative essay:Wiki versus face-to-face interactions. GEMA Online ${ }^{\circledR}$ Journal of Language Studies, 17(2), 33-53. https://doi.org/10.17576/gema-2017-1702-03

Bhowmik, S. K., Hilman, B., \& Roy, S. (2019). Peer collaborative writing in the EAP classroom: Insights from a Canadian postsecondary context. TESOL Journal, 10(2), 1-16. https://doi.org/10.1002/tesj.393

Bikowski, D., \& Vithanage, R. (2016). Effects of web-based collaborative writing on individual L2 writing development. Language Learning \& Technology, 20(1), 79-99.

Chaiklin, S. (2003). The zone of proximal development in Vygotsky's analysis of learning and instruction. In A. Kozulin, B. Gindis, V. S. Ageyev, \& S. M. Miller (Eds.), Vygotsky's educational theory in cultural context (pp. 39-64). Cambridge, NY: Cambridge University Press. https://doi.org/10.1017/CBO9780511840975.004 
Chen, J. S., \& Sujarittanonta, L. (2014). Enhancing intercultural collaborative learning in a multinational classroom: Case of Taiwan. Asian Social Science, 10(15), 221-229. https://doi.org/10.5539/ass.v10n15p221

Chen, W. (2019). An exploratory study on the role of L2 collaborative writing on learners' subsequent individually composed texts. The Asia-Pacific Education Researcher, 28(6), 563-573. https://doi.org/10.1007/s40299-019-00455-3

Cho, H. (2017). Synchronous web-based collaborative writing: Factors mediating interaction among second-language writers. Journal of Second Language Writing, 36, 37-51. https://doi.org/10.1016/j.jslw.2017.05.013

Coffin, P. (2020). Implementing collaborative writing in EFL classrooms: Teachers and students' perspectives. LEARN Journal: Language Education and Acquisition Research Network, 13(1), 178-194.

Conteh, J. (2019). The EAL teaching book: Promoting success for multilingual learners. London: SAGE Publications Inc.

Dobao, A. F. (2012). Collaborative writing tasks in the L2 classroom: Comparing group, pair, and individual work. Journal of Second Language Writing, 21(1), 40-58. https://doi.org/10.1016/j.jslw.2011.12.002

Dobao, A. F. (2014). Attention to form in collaborative writing tasks: Comparing pair and small group interaction. Canadian Modern Language Review, 70(2), 158-187. https://doi.org/10.3138/cmlr.1768

Dong, Y., \& Liu, S. (2020). Dynamic features of students' scaffolding interaction in English writing class. Theory and Practice in Language Studies, 10(6), 647-656. https://doi.org/10.17507/tpls.1006.04

Elabdali, R. (2021). Are two heads really better than one? A meta-analysis of the L2 learning benefits of collaborative writing. Journal of Second Language Writing, 1-16. https://doi.org/10.17507/tpls.1006.04

Folse, K. S., \& Pugh, T. (2020). Great writing 5: from great essays to research (5th ed.). Boston, MA: Cengage Learning.

Forbes, K. (2019). The role of individual differences in the development and transfer of writing strategies between foreign and first language classrooms. Research Papers in Education, 34(4), 445-464. https://doi.org/10.1080/02671522.2018.1452963

Ghufron, M. A., \& Ermawati, S. (2018). The strengths and weaknesses of cooperative learning and problem-based learning in EFL writing class: Teachers' and students' perspectives. International Journal of Instruction, 11(4), 657-672. https://doi.org/10.12973/iji.2018.11441a

Hsiu-Chen Hsu. (2019). Wiki-mediated collaboration and its association with L2 writing development: an exploratory study. Computer Assisted Language Learning, 32(8), 945-967. https://doi.org/10.1080/09588221.2018.1542407

Jacobs, H. L., Stephen, A., Zingkgraf, D. R., Wormuth, V., Faye, H., Jane, B., \& Hughey, J. (1981). Testing ESL composition: A practical approach. Rowley, MA: Newbury House.

Krishnan, J., Cusimano, A., Wang, D., \& Yim, S. (2018). Writing together: Online synchronous collaboration in middle school. Journal of Adolescent \& Adult Literacy, 62(2), 163-173. https://doi.org/10.1002/jaal.871

Lantolf, J. P., \& Thorne, S. L. (2007). Sociocultural theory and second language learning. In VanPatten, B. \& Williams, J. (Eds.), Theories in second language acquisition: An introduction (pp. 197-221). Mahwah, New Jersey: Lawrence Erlbaum.

Latifi, S., Noroozi, O., \& Talaee, E. (2021). Peer feedback or peer feedforward? Enhancing students' argumentative peer learning processes and outcomes. British Journal of Educational Technology, 52(2), 768-784. https://doi.org/10.1111/bjet.13054

Le, H., Janssen, J., \& Wubbels, T. (2018). Collaborative learning practices: teacher and student perceived obstacles to effective student collaboration. Cambridge Journal of Education, 48(1), 103-122. https://doi.org/10.1080/0305764X.2016.1259389

Lewis, R. D. (2006). When cultures collide: Leading across cultures. Boston, MA: Nicholas Brealey Publishing.

Li, M. (2014). Small group interactions in wiki-based collaborative writing in the EAP context. (Unpublished doctoral dissertation). University of South Florida, FL: USA.

Li, M., \& Kim, D. (2016). One wiki, two groups: Dynamic interactions across ESL collaborative writing tasks. Journal of Second Language Writing, 31, 25-42. https://doi.org/10.1016/j.jslw.2016.01.002 
Li, M., \& Storch, N. (2017). Second language writing in the age of CMC: Affordances, multimodality, and collaboration. Journal of Second Language Writing, 36, 1-5. https://doi.org/10.1016/j.jslw.2017.05.012

Li, M., \& Zhu, W. (2013). Patterns of computer-mediated interaction in small writing groups using wikis. Computer Assisted Language Learning, 26(1), 61-82. https://doi.org/10.1080/09588221.2011.631142

Li, M., \& Zhu, W. (2017). Explaining dynamic interactions in wiki-based collaborative writing. Language Learning \& Technology, 21(2), 96-120. https://doi.org/10.1057/978-1-137-51768-5

Li, Y., \& Deng, L. (2019). I am what I have written: A case study of identity construction in and through personal statement writing. Journal of English for Academic Purposes, 37, 70-87. https://doi.org/10.1016/j.jeap.2018.11.005

Limbu, L., \& Markauskaite, L. (2015). How do learners experience joint writing: University students' conceptions of online collaborative writing tasks and environments. Computers \& Education, 82, 393-408. https://doi.org/10.1016/j.compedu.2014.11.024

Lincoln, Y. S., \& Guba, E. G. (1985). Naturalistic inquiry. Newbury Park, CA: SAGE Publications Inc. https://doi.org/10.1016/0147-1767(85)90062-8

Liu, M., Liu, L., \& Liu, L. (2018). Group awareness increases student engagement in online collaborative writing. The Internet and Higher Education, 38, 1-8. https://doi.org/10.1016/j.iheduc.2018.04.001

Lowry, P. B., Curtis, A., \& Lowry, M. R. (2004). Building a taxonomy and nomenclature of collaborative writing toimprove interdisciplinary research and practice. The Journal of Business Communication, 41(1), 66-99. https://doi.org/10.1177/0021943603259363

McDonough, K., \& De Vleeschauwer, J. (2019). Comparing the effect of collaborative and individual prewriting on EFL learners' writing development. Journal of Second Language Writing, 44, 123-130. https://doi.org/10.1016/j.jslw.2019.04.003

McDonough, K., De Vleeschauwer, J., \& Crawford, W. (2018). Comparing the quality of collaborative writing, collaborative prewriting, and individual texts in a Thai EFL context. System, 74, 109-120. https://doi.org/10.1016/j.system.2018.02.010

Neumann, K. L., \& Kopcha, T. J. (2019). Using Google Docs for peer-then-teacher review on middle school students' writing. Computers and Composition, 54, 1-16. https://doi.org/10.1016/j.compcom.2019.102524

Olson, J. S., Wang, D., Olson, G. M., \& Zhang, J. (2017). How people write together now: Beginning the investigation with advanced undergraduates in a project course. ACM Transactions on Computer-Human Interaction (TOCHI), 24(1), 1-40. https://doi.org/10.1145/3038919

Pessoa, S., Mitchell, T. D., \& Miller, R. T. (2018). Scaffolding the argument genre in a multilingual university history classroom: Tracking the writing development of novice and experienced writers. English for Specific Purposes, 50, 81-96. https://doi.org/10.1016/j.esp.2017.12.002

Poehner, M. E., \& Infante, P. (2019). Mediated development and the internalization of psychological tools in second language (L2) education. Learning, Culture and Social Interaction, 22, 1-14. https://doi.org/10.1016/j.lcsi.2019.100322

Rahayu, R. A. (2021). Effect of collaborative writing combined with blog online learning on Indonesian EFL learners' writing skill across motivation. SALEE: Study of Applied Linguistics and English Education, 2(1), 87-98.

Savasci, M., \& Kaygisiz, S. (2019). One hand washes the other and both wash the face: Individuality versus collaboration in L2 writing. Eurasian Journal of Applied Linguistics, 5(1), 131-151. https://doi.org/10.32601/ejal.543789

Storch, N. (2002). Patterns of interaction in ESL pair work. Language Learning, 52(1), 119-158. https://doi.org/10.1111/1467-9922.00179

Storch, N. (2004). Using activity theory to explain differences in patterns of dyadic interactions in an ESL class. Canadian Modern Language Review, 60(4), 457-480. https://doi.org/10.3138/cmlr.60.4.457

Storch, N. (2011). Collaborative writing in L2 contexts: Processes, outcomes, and future directions. Annual Review of Applied Linguistics, 31, 275-288. https://doi.org/10.1017/S0267190511000079

Storch, N. (2013). Collaborative writing in L2 classrooms. Bristol, UK: Multilingual Matters. https://doi.org/10.21832/9781847699954 
Sun, P. P., \& Zhang, L. J. (2020). A multidimensional perspective on individual differences in multilingual learners' L2 Chinese speech production. Frontiers in Psychology, 11(59), 1-14. https://doi.org/10.3389/fpsyg.2020.00059

Suwantarathip, O., \& Wichadee, S. (2014). The effects of collaborative writing activity using Google Docs on students' writing abilities. TOJET: The Turkish Online Journal of Educational Technology, 13(2), 148-156.

Thongchalerm, S., \& Jarunthawatchai, W. (2020). The impact of genre based instruction on EFL learners' writing development. International Journal of Instruction, 13(1), https://doi.org/10.29333/iji.2020.1311a

Tseng, W. T., Liou, H. J., \& Chu, H. C. (2020). Vocabulary learning in virtual environments: Learner autonomy and collaboration. System, 88, 1-17. https://doi.org/10.1016/j.system.2019.102190

Vygotsky, L. S. (1978). Mind in society: The development of higher psychological processes. Cambridge, MA: Harvard University Press.

Wang, D., Olson, J. S., Zhang, J., Nguyen, T., \& Olson, G. M. (2015). DocuViz: visualizing collaborative writing. In Proceedings of the 33rd Annual ACM conference on human factors in computing systems (pp. 1865-1874). ACM. https://doi.org/10.1145/2702123.2702517

Wang, D., Tan, H., \& Lu, T. (2017). Why users do not want to write together when they are writing together: Users' rationales for today's collaborative writing practice. Proceedings of the ACM on Human-Computer Interaction, $1(\mathrm{CSCW}), 1-18$. https://doi.org/10.1145/3134742

Wang, L. (2019). The impact of computer-mediated contexts on interaction pattern of ESL learners in collaborative writing. Technology, Pedagogy and Education, 28(5), 547-562. https://doi.org/10.1080/1475939X.2019.1674183

Warschauer, M., Yim, S., Lee, H., \& Zheng, B. (2019). Recent contributions of data mining to language learning research. Annual Review of Applied Linguistics, 39, 93-112. https://doi.org/10.1017/S0267190519000023

Woodrich, M., \& Fan, Y. (2017). Google Docs as a tool for collaborative writing in the middle school classroom. Journal of Information Technology Education Research, 16, 391-410. https://doi.org/10.28945/3870

Yanguas, I. (2020). L1 vs L2 synchronous text-based interaction in computer-mediated L2 writing. System, 88, 1-11. https://doi.org/10.1016/j.system.2019.102169

Yim, S., Wang, D., Olson, J. S., Vu, V., \& Warschauer, M. (2017). Synchronous writing in the classroom: Undergraduates' collaborative practices and their impact on text quality, quantity, and style. In Proceedings of the Conference on Computer Supported Cooperative Work, CSCW (Vol. 17), Portland, Oregon, USA. https://doi.org/10.1145/2998181.2998356

Yin, R. K. (2018). Case study research and applications: Design and methods (6th ed.). Thousand Oaks, CA: SAGE Publications Inc.

Zhang, M. (2018). Collaborative writing in the EFL classroom: The effects of L1 and L2 use. System, 76, 1-12. https://doi.org/10.1016/j.system.2018.04.009

Zhang, M. (2019). Towards a quantitative model of understanding the dynamics of collaboration in collaborative writing. Journal of Second Language Writing, 45, 16-30. https://doi.org/10.1016/j.jslw.2019.04.001

Zhao, H. (2018). New insights into the process of peer review for EFL writing: A process-oriented socio-cultural perspective. Learning and Instruction, 58, 263-273. https://doi.org/10.1016/j.learninstruc.2018.07.010 
Appendix A (Pre-task questionnaire)

1. Gender:

2. Nationality:

3. No. of years of learning English:

4. How will you rate your English proficiency level?

5 . Have you ever participated in any collaborative writing project?

6. Have you ever used Google Docs for your writing assignments?

7. Your learning style is perceived to be more on: self-oriented (prefer individual work)

pair-oriented (prefer pair work) group-oriented (prefer group work) mixed (prefer both individual and group work)

8. Your attitude toward collaborative writing activity is:

Appendix B (Post-task questionnaire)

Answer the following questions.

1. Express your thoughts about the advantages/disadvantages of CW tasks in Google Docs.

2. Describe your role in your group writing tasks.

3. Express your overall impression of CW tasks in Google Docs.

4. Leave some comments or recommendations to improve the collaborative writing tasks.

Appendix C (Guiding questions for semi-structured interviews)

1. Describe how you felt about your CW tasks in Google Docs.

2. How did your group divide up your tasks?

3. What was your responsibility when you were engaged in the CW tasks?

4. What is your goal in working in small groups?

5. What are the advantages and disadvantages of working in small groups?

6. How would you describe your overall impression of CW tasks?

\section{Copyrights}

Copyright for this article is retained by the author(s), with first publication rights granted to the journal.

This is an open-access article distributed under the terms and conditions of the Creative Commons Attribution license (http://creativecommons.org/licenses/by/4.0/). 